\title{
Using Mobile Devices as Effective Learning Tools in a Library Setting
}

\author{
Margo Pickworth \\ Shore Preparatory School \\ PO Box North Sydney. \\ Australia \\ mpickworth@shore.nsw.edu.au
}

\begin{abstract}
Mobile devices are prolific and young people have embraced this technology in all facets of their lives. Using a small number of iTouch and iPad devices in a school library has provided students rich learning opportunities which have enhanced cognitive, personal and interpersonal skills.

By harnessing their power and motivation, mobile devices can become powerful learning tools. Integrating $Q R$ codes, Student response apps, Thinking and Presentation tools have been used to develop cognitive skills. This article will explain, justify and provide illustrations of practice of how these devices have been used and demonstrate their value in making connections in the school library.
\end{abstract}

Keywords: Mobile learning, Apps, digital culture,

\begin{abstract}
Background
The Educause 2012 Horizon Report cited the areas of emerging technology within one year or less, as Mobile Apps and Tablet Computing. This would appear to be an accurate prediction as smartphones, tablets, mobile music, sound and video devices have become everyday household objects. As a Teacher Librarian in a school, in order to remain current and connected it is important to embrace and integrate this technology.
\end{abstract}

\section{Context}

The context is a school library in well-established boys' school in North Sydney Australia where the teacher librarian works co-operatively with classroom teachers to develop both literacy and inquiry skills integrated into NSW English and HSIE syllabi.

In 2010 ten iTouch devices were purchased followed by the purchase of fifty iPads in 2012 for exclusive use in library teaching. This was supported by dedicated wireless technology as well as a MacBook to be used as an aggregator. The acquisition of this technology was accompanied by an enthusiasm for learning, a positive attitude and a willingness to embark on a journey of discovery with young male students at the helm!

Although there is wide range of tools available the focus of this article will be as follows:

- QR codes which have been used to promote critical and creative thinking

- Student Response systems using quiz formats for assessment of learning 
- Thinking/Organising Tools to provide frameworks for thinking

- Presentation Tools to provide a range of methods for showcasing learning

\section{QR Codes}

A QR Code is a type of barcode that is readable by dedicated QR barcode readers on Smartphones and other handheld devices such as iTouches and camera phones. The code consists of black modules arranged in a square pattern on a white background. They can be easily created using a QR generator and contain information that may be text, image or link to website, email, or other data.

While QR codes have been in existence for quite some time in business - they were initially used initially to track product parts in Japan, they are also appearing in school libraries and classrooms! While it may have not been the original intention of the creators, QR codes also have unlimited potential in the environment of the 21 st century learner.

QR Codes can be created using three easy steps. Firstly, the Code is created using a QR Generator program. There are many available, searchable through Google, including GOQRME. Next, paste in the URL, piece of text, then generate which creates the code It is then created and becomes printable. A QR reader program needs to be installed on student devices. Simply open the app, point at the code and the object appears.

The use of QR Codes is only limited by our imagination. They are flexible, dynamic and powerful learning tools. QR Codes can:

- Take students to websites without the need to type their address.

- Provide information 'hot spots' in the Library to access online videos, websites, text that are related to curriculum and instructional material.

- Adapt text/books by including QR Codes which provide additional information via text, video and audio (even in an alternative language)

- Take students to a website you are browsing on an interactive whiteboard.

QR codes have been used in a range of library environments. Walsh (2010) reports that University of Huddersfield has used QR codes on shelf ends, printed handouts, signage, inside books, next to printers, on computers and instructional documents. O'Connor (2002) reported that QR codes are particularly effective in settings which cater for students with disabilities. By providing an alternative access format for students who need additional support in reading and writing they are able to quickly gain access to information while also incorporating the use of their own literacy support apps or software. Using a QR Code enables users to navigate to a website instantly without typing or scanning. Using QR Codes with instructions enables users with low literacy levels to connect with their text-to-speech app.

QR codes can also link the physical and virtual worlds by allowing students to link to more information about an object or historically significant building or area. They can bring learning into the physical world and out of the library. Essentially, the power of QR codes is in their ability to allow learners to use their mobile devices to link to specific information on the internet quickly and easily. Their connection to mobile learning appears to be a natural one as it is often a mobile device that is used to decode the QR codes and to access the information provided through the QR code on the Internet. 
QR codes make links to the outside world. They expand the horizons of the library, keeping it relevant and up to date. They also provide an exciting and motivating way of learning.

\section{Student Response Apps}

Student Response apps allow for student-teacher interaction in the digital world. One excellent tool that is quick and easy to use is Socrative. This is a smart student response system that empowers teachers to engage their classrooms through a series of teachercreated educational games and exercises via mobile devices. The strength of the app is the ability to tailor the activity to suit the particular library context.

It is necessary to first download the Student app on student devices and the Teacher app on the teacher device. The teacher is then able to set up a room number, followed by the creation of a quiz which can be either multiple choice or short answer. The quiz can then be sent electronically to students, via the wireless network, either at student pace or teacher directed pace. Instant feedback is provided to both student and teacher, checking understanding and demonstrating student progress.

The use of this app is once again, limited only by the users imagination. In a school library setting it can be used a revision of inquiry skills, sequencing of text, literal and inferential comprehension of visual, audio and print text. Other examples could include treasure hunts for Dewey numbers and locating items in the library. Students are also able to construct quizzes for their peers, which can ultimately provide student ownership of their library learning.

\section{Thinking/Organising Tools}

Thinking/Organising apps on mobile devices provide rich tools for developing a range of cognitive skills, particularly in the area of inquiry. Tools4Students and Popplet are two particularly effective examples, especially for mind-mapping and data recording.

Popplet can be used for many of the stages of inquiry learning including making a research plan, and brainstorming possible sources of information. As information is gathered this stage can be supported in activities such as recording notes and relevant ideas as students begin to organise their information. Popplet is also an excellent tool for reflection at the completion of the inquiry process as students reflect on their progress.

Tools4Students has also been used for wide range of stages of inquiry such as sorting out information with a particular focus on note-taking. It contains a wide range of graphic organisers such as timelines, cause and effect analysis and comparison charts.

\section{Presentation Tools}

Presentation Tools can also be used effectively on mobile devices. A wide range of apps are available such as Puppet Pals, iMovie, Animoto. It is also possible to create and view book trailers on mobile devices. In this process book trailers are first created in Moviemaker, saved onto school learning management system, and then uploaded onto the iTouch device for the rest of the school to view at their leisure. iMovie, Puppet Pals have also been used as creative and reflective tools. 


\section{Conclusion}

Using mobile devices encourages active and independent learning. They provide opportunities for students to transform from passive recipients of information to active meaning-makers, working with their teachers to co-design and personalise their learning. Mobile devices can cater for all learning styles by providing information in auditory, visual and print form. Their effectiveness with student with disabilities has been well documented.

Mobile devices can also challenge the teachers' role in the library. They require a type of pedagogy that challenges some of the traditional means of classroom control. The mobile nature of these technologies together with the collaborative and creative activities students might undertake with them, necessarily require students to be moving around rather than sitting at desks. Students and teachers will be making different uses of library space, which can be potentially unsettling at first.

As well as presenting more opportunities for independent learning, using mobile devices can make connections between school library and out of school experiences. This may require us to move beyond a focus on curriculum content to locating different kinds of resources and engaging with students' lives and cultures outside of school, to make our library more relevant and effective to our students.

\section{References}

NMC New Media Horizon Report (2013) Retrieved from

http://www.nmc.org/pdf/2013-horizon-report-k12.pdf

O'Connor, G (2002) QR codes - what are they and how can I use them in my classroom?

Retrieved from http://www.spectronicsinoz.com/blog/apps-and-mobile-learning/qr-codeswhat-are-they-and-how-can-i-use-them-in-my-classroom/

Lorenzo, R QR codes and mobile learning (2010) Retrieved from

http://themobilelearner.wordpress.com/2010/11/17/qr-codes-and-mobile-learning/

Educause (2009) 7 things you should know about QR codes Retrieved from http://net.educause.edu/ir/library/pdf/ELI7046.pdf

Walsh, A (2010) QR Codes - using mobile phones to deliver library instruction and help at the point of need. Journal of Information Literacy Vol 4 (1) Retrieved from

http://ojs.Iboro.ac.uk/ojs/index.php/JIL/article/view/LLC-V4-I1-2010-1/1450 


\section{Biographical Note}

Margo Pickworth is currently the Teacher Librarian at Shore Preparatory School, North Sydney. She has completed a Master of Education (Teacher Librarianship) and Master of Arts (E-Learning). Her teaching career has spanned a wide variety of contexts including primary and tertiary in both the public and independent sectors. Her current interest is in how technology can assist students (particularly boys) in enjoying and engaging in literature as well as experimenting with new mobile technologies to keep the school library relevant in today's fast-moving world. 